\title{
Ficções neurocientíficas e a medicalização das subjetividades na contemporaneidade
}

\author{
Neuroscientific fictions and the medicalization of subjectivities \\ in contemporaneity
}

Ficciones neurocientíficas y la medicalización de las subjetividades en la contemporaneidad

\begin{abstract}
ANATOMIA DE UMA EPIDEMIA: PÍLULAS MÁGICAS, DROGAS PSIQUIÁTRICAS E O AUMENTO ASSOMBROSO DA DOENÇA MENTAL. Whitaker R. Rio de Janeiro: Editora Fiocruz; 2017. 421 p. ISBN 9788575414927
\end{abstract}

doi: 10.1590/0102-311X00005818

Robert Whitaker, jornalista investigativo, foi ousado ao escolher como objeto de pesquisa os transtornos mentais e sua gestão contemporânea, pautada quase que exclusivamente no uso de psicotrópicos. No livro Anatomia de uma Epidemia: Pílulas Mágicas, Drogas Psiquiátricas e o Aumento Assombroso da Doença Mental, o autor elege um enigma a ser desvendado: por que o número de doentes mentais inválidos teve um aumento vertiginoso nos últimos 50 anos nos Estados Unidos apesar da Revolução Psicofarmacológica da década de 1950?

Ao iniciar o estudo, Whitaker não duvidava de que os pesquisadores houvessem descoberto as causas das doenças mentais e que tal conhecimento ajudaria no desenvolvimento de drogas para controlar os "desequilíbrios" da química cerebral. Porém, sua exaustiva pesquisa desvendou não apenas que o progresso na identificação das causas biológicas dos distúrbios mentais e o desenvolvimento de drogas eficazes para estas condições são uma ilusão, mas também que o paradigma de tratamento medicamentoso vem alimentando a epidemia de doenças mentais incapacitantes.

O autor entrevistou usuários e ex-usuários de psicotrópicos, frequentou manicômios, reuniões de médicos com pacientes, sessões grupais; pesquisou em jornais, revistas científicas e congressos médicos. Sobretudo com base na exposição de algumas histórias reais evidencia a complexidade da relação dos sujeitos com a medicação e com suas supostas doenças, além da estreiteza que é presumir que conflitos subjetivos possam ser resumidos a desequilíbrios químicos que clamam por medicamentos.

Dessa perspectiva, o autor reatualizou dois pontos interligados e extremamente caros para aqueles interessados na problemática da medicalização e, sobretudo, no campo do mental. Tratase da produção, pela medicina, de verdades e de doenças. Na década de 1960, os teóricos clássicos da medicalização criticavam a crescente extensão da medicina para campos que até então não lhe pertenciam, o que fez emergir conflitos acerca do estatuto médico, social, epistêmico e ontológico das doenças.

A autoridade para definir e tratar as condições desviantes pressupõe a construção de verdades sobre elas. A partir da constituição da Medicina Moderna, a leitura religiosa do desvio, baseada no ideário cristão de salvação, foi subvertida e se enunciou a problemática da cura, donde os discursos médicos passaram a regular as práticas e laços sociais de forma colossal ${ }^{1}$. 
Essa é a grande novidade da modernidade que sobrevive nos dias de hoje: a fantasia de que o discurso científico da medicina é produtor de verdades inquestionáveis. Nessa seara, as questões são muitas: O discurso médico é um discurso científico? O discurso psiquiátrico é um discurso médico? Há um único modelo de cientificidade? O que é um discurso científico? O discurso científico é um discurso verdadeiro?

Whitaker não tem pretensões epistêmicas e não se aventura em promover um debate sobre a relação entre ciência e verdade, mas mostra de forma bem fundamentada que apesar da história contada pela Psiquiatria ser a de uma ciência rigorosa em ação, a realidade é muito distante disto. Os cientistas não identificaram qualquer processo patológico ou anormalidade cerebral que pudesse causar os sintomas dos quais os pacientes se queixam. O autor afirma a inexistência de estudos bem conduzidos de longo prazo sobre os efeitos dos psicotrópicos. Também desbanca, com expressiva consistência teórica, a teoria do desequilíbrio químico dos transtornos mentais.

Whitaker não se limita a apontar a fragilidade da Psiquiatria como saber científico, mas nos mostra que diversos estudos evidenciaram a ineficácia das drogas psiquiátricas. Outros demonstraram eficácia comprovada de alguns medicamentos em termos de alívio de sintomas em curto prazo e um desastroso desfecho a longo prazo. A evidência de que a maioria dos psicotrópicos tem efeitos benéficos a curto prazo mas cobram um alto preço a longo prazo, tanto em termos físicos quanto psíquicos, é o dado mais importante do livro. Ela nos faz entrar no segundo ponto caro aos estudiosos da medicalização: a produção de doenças.

Uma das faces clássicas da medicalização é a expansão das fronteiras diagnósticas ou a classificação de condições próprias da vida como transtornos mentais, passíveis de tratamento médico. Whitaker reafirma essa realidade na atualidade da Psiquiatria, sobretudo no que se refere à bipolaridade e à patologização dos comportamentos de crianças e adolescentes. Autores contemporâneos têm chamado de disease mongering 2 a arte de "vender" doenças novas ou de alargar os limites das categorias diagnósticas já existentes como forma de aumentar o mercado de consumo das drogas psiquiátricas. Outros autores têm usado o termo farmacologização 3 para expressar a medicalização contemporânea, fortemente pautada na transformação de condições humanas em oportunidades para intervenções farmacológicas.

O jornalista nos mostra ainda que os medicamentos são verdadeiras armadilhas, no sentido de promoverem um alívio sintomático a curto prazo, mas perturbarem um sistema de neurotransmissores que promove adaptações compensatórias do cérebro. Em consequência dessas mudanças, a pessoa que retira o medicamento torna-se vulnerável a recaídas, o que provoca a ilusão de que a droga é indispensável.

Mas Whitaker argumenta que são as próprias drogas - e não as doenças - as responsáveis pela recaída. $\mathrm{O}$ uso contínuo das drogas psiquiátricas causa doenças mentais incapacitantes e tem gerado uma epidemia de doentes mentais crônicos. Illich 4 diria que estamos diante de uma iatrogênese clínica, isto é, que parte dos distúrbios psiquiátricos de hoje são doenças criadas na medida em que são condições clínicas das quais os medicamentos, os médicos e as instituições de saúde são os agentes patogênicos.

Whitaker se pergunta por que, apesar das evidências, a sociedade acredita na existência de uma "revolução psicofarmacológica". A problematização desse aspecto é, talvez, a maior fragilidade do trabalho. $\mathrm{O}$ autor reduz a vitória da Psiquiatria Biológica ao esforço de psiquiatras em superar a imagem da fragilidade científica própria da especialidade. Faz referência ao empenho dos psiquiatras em reabilitar a imagem dos psicotrópicos e contar a história dos transtornos mentais dentro de uma perspectiva centrada exclusivamente no modelo biomédico, fortemente associado à verdade científica no imaginário social.

Como resposta à perda de mercado para outras terapias, que se mostraram mais eficazes, configurou-se aquilo que Whitaker denominou de uma "aliança espúria” entre a indústria 
farmacêutica e os psiquiatras. De fato, o autor tem bons argumentos para sustentar essa premissa. Porém, por não se aprofundar na reflexão sobre o que está em jogo em tal ilusão social, acaba por se aproximar de uma apreensão ortodoxa do fenômeno da medicalização, perdendo a oportunidade de refinar a problemática.

Poderíamos perguntar o que incita as subjetividades contemporâneas a se inscreverem tão facilmente no circuito da farmacologização. Van Der Geest \& Whyte 5 sugerem que os medicamentos, em sua concretude, são commodities que facilitam processos simbólicos e sociais. Eles indicam que a cura pode ser objetificada. Sabemos do poder atrativo das pílulas em uma governamentalidade neoliberal, cujo capital humano é o novo bem a ser investido ${ }^{6}$. A psicofarmacologia, pautada num discurso que naturaliza a condição humana, serve bem para as subjetividades contemporâneas forjadas no registro do empresariamento de si e da exigência de performance.

Remediar o mal-estar tornou-se sinônimo de medicar o mal-estar. A força da indústria farmacêutica é inquestionável, mas ela e os médicos não conseguiriam, sozinhos, fazer do medicamento este objeto de desejo privilegiado da atualidade. O alívio da dor a curto prazo certamente é um dado fundamental para entendermos o apelo às drogas. Mas devemos considerar também, com Birman ${ }^{7}$, que a experiência psíquica contemporânea é marcada pelo triunfo da dor sobre o sofrimento. O apelo ao outro está em baixa e é precisamente ele que possibilita a trans- formação da dor em sofrimento ao promover processos de simbolização e criação de novos circuitos pulsionais. Os medicamentos servem ao registro da dor, em que não há apelo ao outro. Nesse sentido, o trabalho de Whitaker é uma leitura imprescindível, pois nos incita a rever o paradigma de cuidado pautado no uso contínuo de psicotrópicos.

\section{Paula Gaudenzi}

1 Instituto Nacional de Saúde da Mulher, da Criança e do Adolescente Fernandes Figueira, Fundação Oswaldo Cruz, Rio de Janeiro, Brasil.

paula.gaudenzi@gmail.com

1. Foucault M. O nascimento da clínica. São Paulo: Forense Universitária; 2005.

2. Healy D. The latest mania: selling bipolar disorder. PLoS Med 2006; 3:e185.

3. Williams SJ, Martin P, Gabe J. The pharmaceuticalisation of society? A framework for analysis. Sociol Health Illn 2011; 33:710-25.

4. Illich I. A expropriação da saúde. Nêmesis da medicina. Rio de Janeiro: Nova Fronteira; 1975.

5. Van Der Geest S, Whyte SR. O encanto dos medicamentos: metáforas e metonímias. Sociedade e Cultura 2011; 14:457-72.

6. Foucault M. Nascimento da biopolítica: curso no Collège de France. São Paulo: Martins Fontes; 2008.

7. Birman J. O sujeito na contemporaneidade: espaço, dor e desalento na atualidade. Rio de Janeiro: Civilização Brasileira; 2012. 